\title{
EXTRATO DE Thymus vulgaris L. (TOMILHO) ATUA SOBRE BIOFILME POLIMICROBIANO DE Candida albicans e Streptococcus mutans
}

\author{
Fábia Lugli Sper ${ }^{1}$ \\ Jonatas Rafael de Oliveira ${ }^{2}$ \\ Leandro Wagner Figueira ${ }^{3}$ \\ Daiane de Jesus ${ }^{4}$ \\ Vanessa Marques Meccatti ${ }^{5}$ \\ Cláudio Antonio Talge Carvalho ${ }^{6}$ \\ Luciane Dias de Oliveira ${ }^{7}$
}

Resumo: As folhas de tomilho são utilizadas como condimento, conservante alimentício e para fins medicinais. O objetivo desse estudo foi avaliar a ação antimicrobiana do extrato de tomilho sobre biofilme composto por $C$. albicans e $S$. mutans. Para tanto, suspensões de cada micro-organismo foram ajustadas a $10^{7} \mathrm{UFC} / \mathrm{mL}$ e adicionadas (100 $\mu \mathrm{L} /$ poço de cada) em placa de microtitulação. Após 90 min de incubação, o sobrenadante foi substituído por $200 \mu \mathrm{L}$ poço de BHI+YNB (1:1). O biofilme de $48 \mathrm{~h}$ foi exposto por 5 min ao extrato de tomilho ou à solução salina. Após lavagens com salina, $100 \mu \mathrm{L} /$ poço de solução de MTT foi adicionada e incubada por $1 \mathrm{~h}$, esta solução foi substituída por dimetilsulfóxido (100 $\mu \mathrm{L} / \mathrm{poço}$ ) e a placa foi incubada por mais 10 min e agitada por outros $10 \mathrm{~min}$. Os valores de densidade óptica (DO) foram obtidos em $\lambda=570 n m$ e convertidos em percentual de viabilidade, analisados estatisticamente por T-Test $(p \leq 0,05)$. $O$ extrato de tomilho reduziu significativamente a viabilidade do biofilme polimicrobiano (64 $\pm 11 \%$ ). Com isso, foi constatado o efeito antimicrobiano do extrato de tomilho sobre o biofilme composto por $C$. albicans e S. mutans.

Palavras-chave: Thymus vulgaris, Candida albicans, Streptococcus mutans, Biofilme polimicrobiano.

\footnotetext{
${ }^{1}$ Laboratório de Microbiologia e Imunologia/UNESP, Brasil. E-mail: fabiafarma@hotmail.com.

2 Laboratório de Microbiologia e Imunologia/UNESP, Brasil. E-mail: jroliveira16@hotmail.com.

${ }^{3}$ Laboratório de Microbiologia e Imunologia/UNESP, Brasil. E-mail: leandrowf@live.com.

${ }^{4}$ Laboratório de Microbiologia e Imunologia/UNESP, Brasil. E-mail: daianej1@gmail.com.

5 Laboratório de Microbiologia e Imunologia/UNESP, Brasil. E-mail: vanessa.tep@hotmail.com.

6 Laboratório de Microbiologia e Imunologia/UNESP, Brasil. E-mail: claudiotalge@ict.unesp.br.

7 Laboratório de Microbiologia e Imunologia/UNESP, Brasil. E-mail: luciane@ict.unesp.br.
} 